\title{
EPIDEMIOLOGICAL CONSEQUENCES OF THE MECHANICAL TRANSMISSION OF MYXOMATOSIS BY MOSQUITOES*
}

\author{
BY FRANK FENNER, $\dagger$ M. F. DAY $\ddagger$ AND GWENDOLYN M. WOODROOFE $\dagger$
}

(With 1 Figure in the Text)

Recent quantitative studies of the complex relationships between the virus, insect vectors and vertebrate hosts of eastern equine encephalomyelitis have shown that with this virus, which multiplies in the insect vector, several factors influence host and vector potential (Schaeffer \& Arnold, 1954; Chamberlain, Corristan \& Sikes, 1954; Chamberlain, Sikes, Nelson \& Sudia, 1954; Chamberlain, Kissling \& Sikes, 1954). Among these are the thresholds of infection for different mosquito species; the transmission rates and infection rates of different species of mosquitoes which have engorged on high concentration of virus in the vertebrate hosts; and the intensity and duration of viraemia in the vertebrate hosts.

Quite different quantitative factors influence the transmission of myxomatosis by mosquitoes, for this has been shown to be purely mechanical in nature (Fenner, Day \& Woodroofe, 1952; Day, Fenner, Woodroofe \& McIntyre, 1956). Although we earlier described the mosquito as comparable to a 'flying pin', the relative capacity of different mosquitoes to transmit myxomatosis may be influenced by their biting habits, by the anatomy of their mouthparts, and by their propensity for repeated feeding if interrupted. Furthermore, different strains of the virus may differ in their transmissibility, due, not to the intensity and duration of viraemia as in the encephalitides, but to the degree of multiplication of the virus in the skin, and the average duration of life of rabbits in an infectious condition. The present paper is concerned with these and other factors which may be of major epidemiological importance in their influence on the competition between virus strains of differing virulence.

\section{MATERIALS}

Several strains of myxoma virus were used. Their origin, their virulence and the clinical features of infection of rabbits by these different strains have been described in detail elsewhere (Fenner \& Marshall, 1956). Certain factors relevant to the present study are summarized in Table 1.

The sources of mosquitoes, fertile eggs, and rabbits were described in the preceding paper (Day et al. 1956).

* Aided by a grant from the Rural Credits Development Fund of the Commonwealth Bank of Australia.

$\dagger$ Department of Microbiology, John Curtin School of Medical Research, Australian National University, Canberra, Australia.

$\ddagger$ Division of Entomology, Commonwealth Scientific and Industrial Research Organization, Canberra, Australia. 


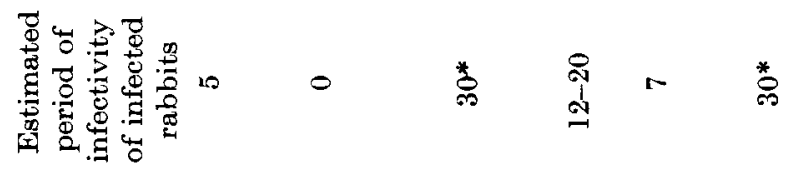

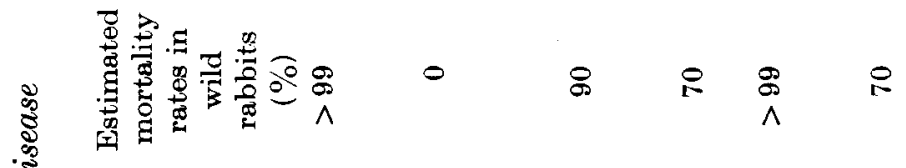

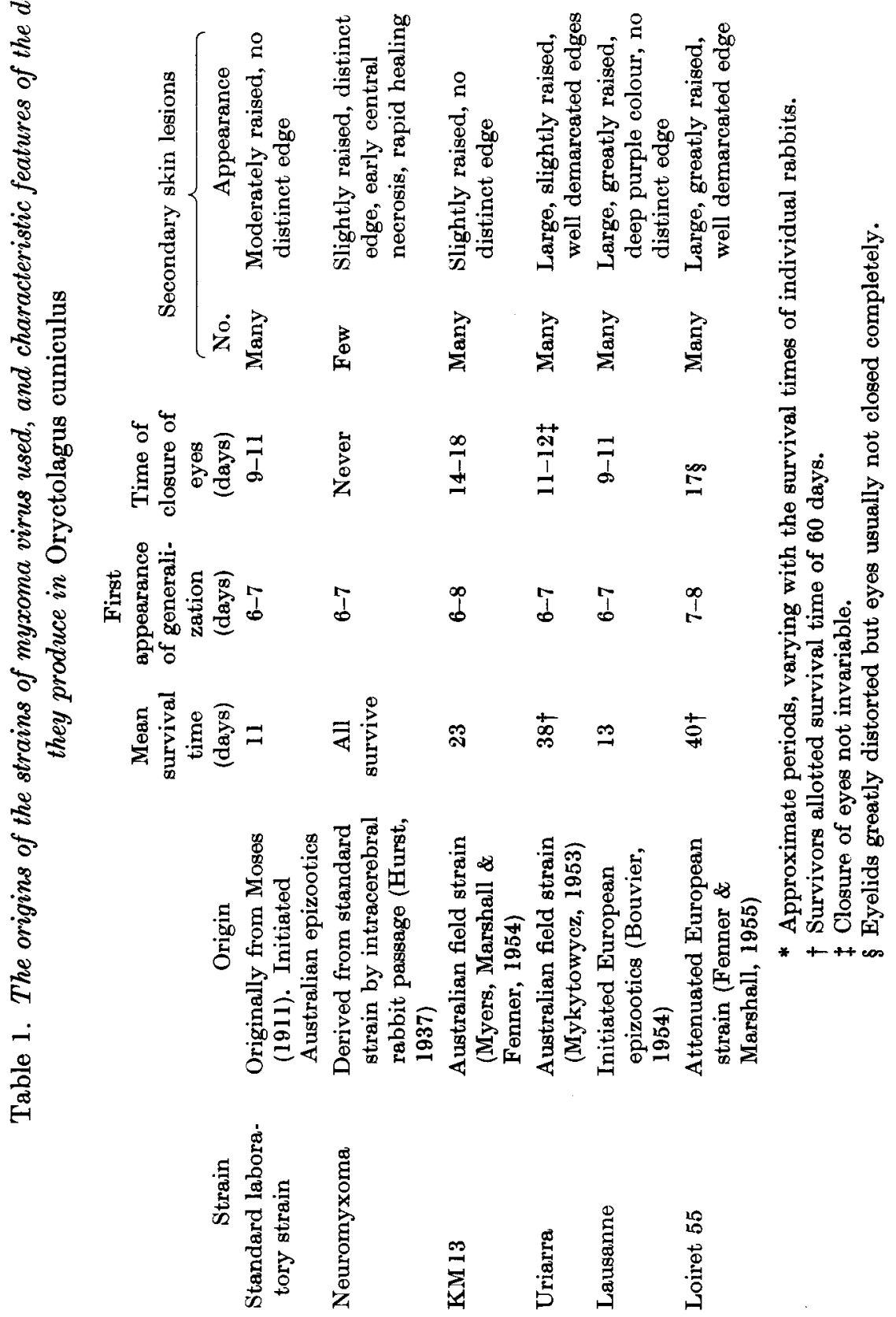




\section{METHODS}

Methods for the titration of myxoma virus in rabbits and eggs have been described in detail elsewhere (Fenner \& McIntyre, 1956). It was shown that, for several strains of myxoma virus, one egg-infectious dose was equivalent to 2.5 rabbitinfectious doses. Throughout this paper virus titres have been expressed as rabbitinfectious doses.

Neutralizing antibody to myxoma virus was titrated on the chorioallantois by the pock-counting method (Lush, 1937; Fenner \& Woodroofe, 1953).

Methods for grinding mosquitoes or parts thereof, and skin slices from infected rabbits, were described in the previous paper (Day et al. 1956).

\section{EXPERIMENTAL RESULTS}

Skin titres attained by different strains of virus

Whereas the intensity and duration of viraemia are the important features of vertebrate infections with viruses transmitted after multiplication in the mosquito, the concentration of virus in the skin is of major importance among viruses transmitted mechanically. Earlier experiments (Fenner et al. 1952) showed that rabbits did not become infectious until obvious skin lesions appeared, and infection was related to probing through such lesions and not to engorgement with blood containing virus. It was important to determine whether different strains of myxoma virus differed in the virus titre attained in the superficial cells of the skin, and if so whether such variations could be correlated with differing efficiency of transmission by mosquitoes. The rate and extent of multiplication of the six strains of myxoma virus were determined in the following manner. With each virus strain two rabbits were inoculated intradermally in ten marked skin sites with $0.1 \mathrm{ml}$. inocula, each containing $10^{4-3}$ rabbit-infectious doses. At intervals of 1 or 2 days thereafter, slices of skin from the lesions occurring at the site of the inoculations were ground as described in the previous paper, and titrated on the chorioallantois of developing chick embryos. One skin slice was taken from each rabbit. The titres obtained are shown in Table 2, as rabbits 1 and 2 of each group. During the course of other experiments Dr R. Mykytowycz titrated skin slices from the backs of rabbits inoculated with about $4 \times 10^{2}$ rabbit-infectious doses of the standard laboratory strain, the Uriarra III strain, and neuromyxoma virus. His experiments were directed especially to the study of the very early stages of multiplication which are not relevant to the present study. However, he has kindly allowed us to use his data for the second day on, and these are included as rabbit numbers 3 and 4 in the standard, Uriarra III and neuromyxoma figures shown in Table 2. Table 2 also includes figures obtained in a large number of other experiments carried out during the last two years. These indicate the consistency of the titres observed at various stages of infection with different strains of virus, and include figures obtained in the later stages of infection with attenuated strains.

The curves shown in Fig. 1 were derived from the results obtained with rabbits 1 and 2 in each group. 


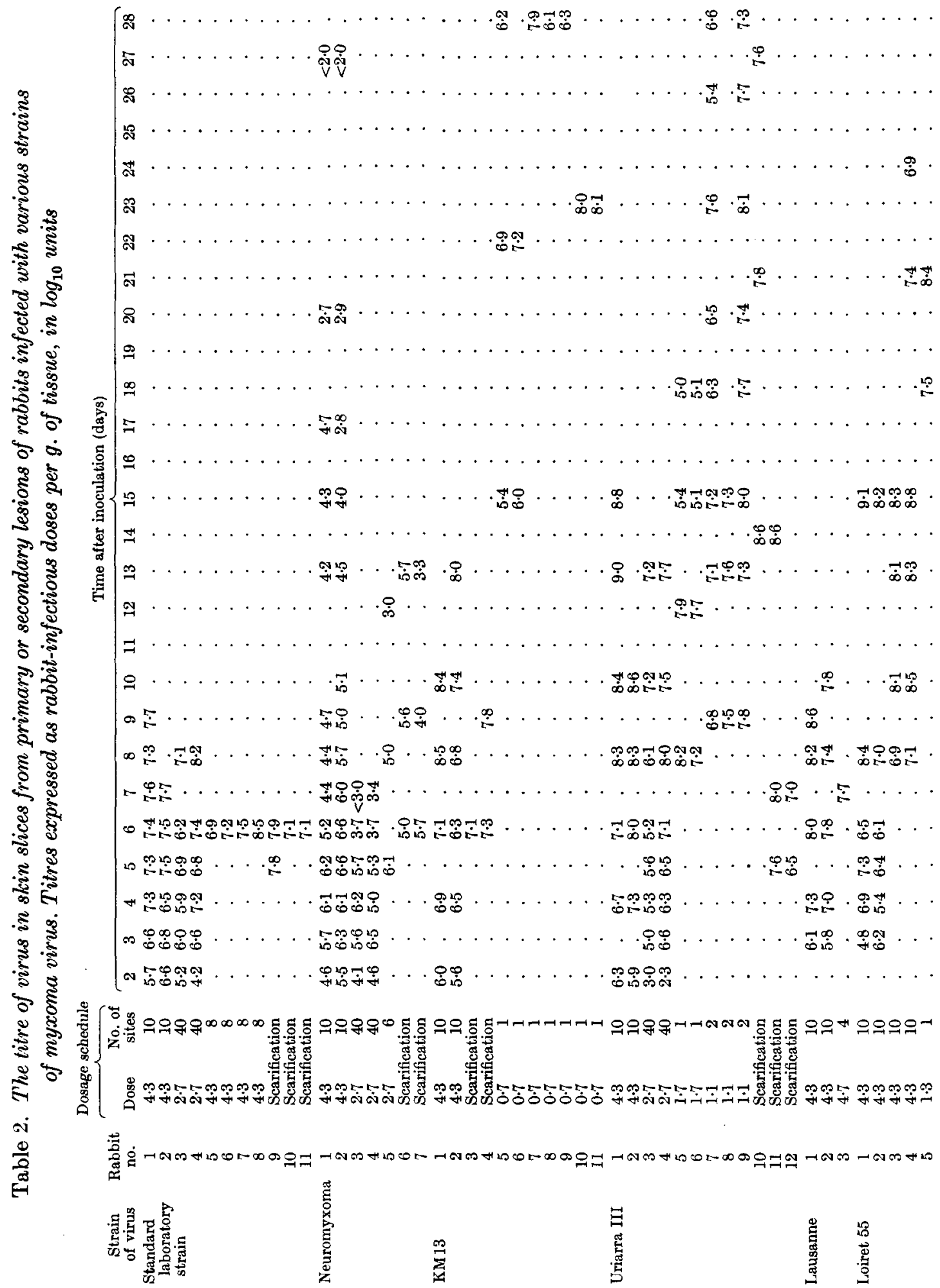


To check the reliability of the results obtained with different strains of myxoma virus growing in different rabbits, each of three rabbits was inoculated intradermally with $0.1 \mathrm{ml}$. doses containing between $10^{4}$ and $10^{5}$ rabbit-infectious doses of five of the strains of virus under investigation. Skin slices were removed from the lesions produced by each strain of virus on the sixth, seventh, eighth and tenth days, and titrated as before. The results shown in Table 3 also include titres obtained with another rabbit examined on the sixth day only (rabbit 4). On the whole, there was good agreement between the titres obtained in the serial titrations on separate

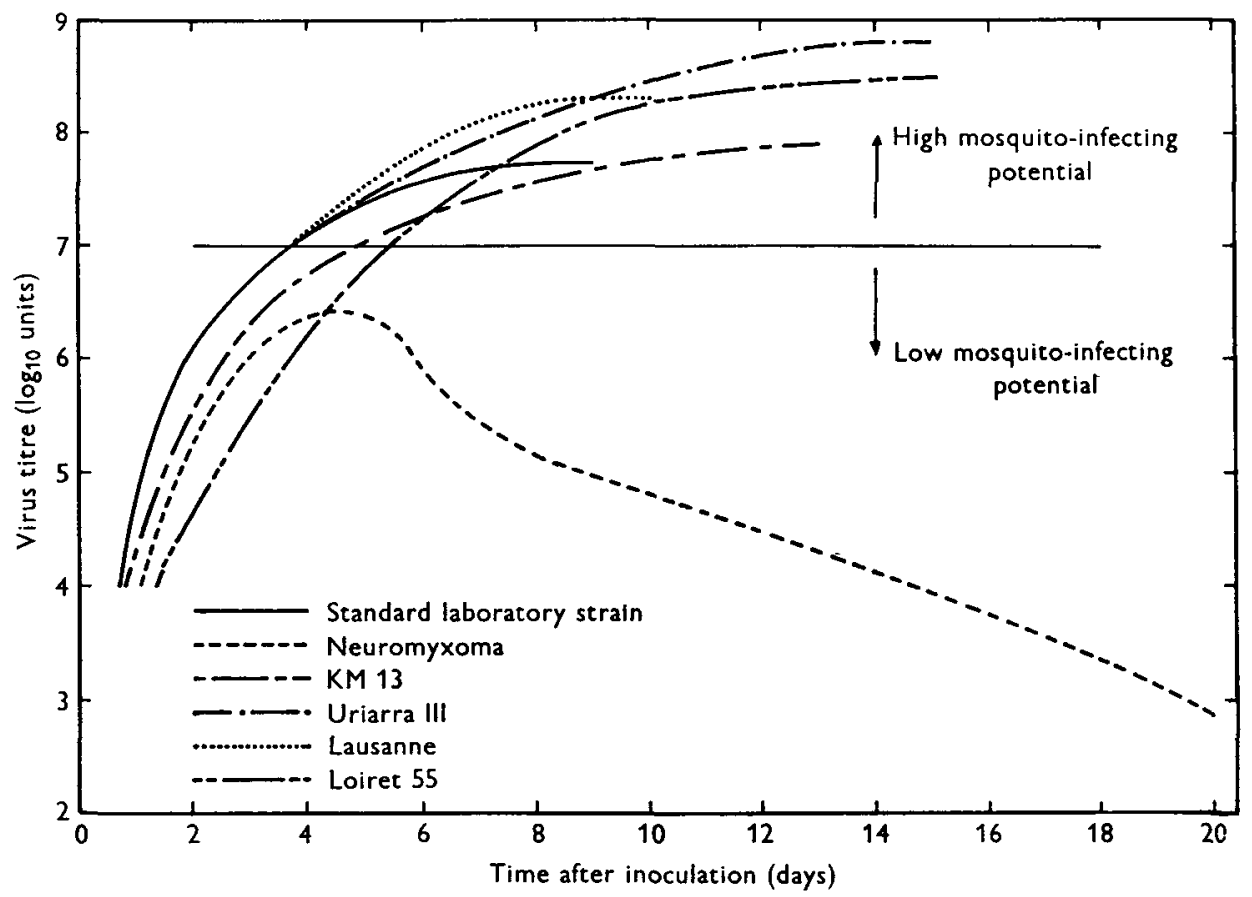

Fig. 1. The titre of virus in slices of skin taken from the surface of lesions produced by the intradermal inoculation of rabbits with large doses (10 $0^{4 \cdot 3}$ rabbit-infectious doses) of various strains of myxoma virus.

rabbits, and titrations from lesions resulting from the simultaneous inoculation of rabbits with several strains of virus.

The highly virulent strains (standard laboratory strain and Lausanne) killed all inoculated rabbits by the tenth day. Rabbits inoculated in several skin sites with large doses of the KM 13 strain died on the tenth and thirteenth days, with Uriarra III on the tenth and fifteenth and with Loiret 55 on the fifteenth and twentyfourth days. Neuromyxoma was not fatal, even in the large doses used in this experiment. Except for neuromyxoma, the skin titres in more chronic cases could be obtained only from animals inoculated in a single site with a small dose of virus. In these the primary lesion was sampled in the early stages of the infection, and later such secondary lesions as remained fleshy and showed the least sign of regression were used for virus titrations. 
In the acute phase the skin titres of most strains behaved in a similar manner. The virus concentration rose steeply between the time of inoculation and the fourth or fifth day, and then flattened off from the seventh or eighth day. Neuromyxoma was an obvious exception, as the low peak titre was reached on the fourth day and the lesions rapidly regressed, with falling virus titres, after the sixth day. The rise in skin titre of the Loiret 55 strain appeared to be somewhat more gradual than with the other strains, but the peak titres were much the same.

In the later stages of infection with the slightly attenuated strains (KM13, Uriarra III and Loiret 55) the progress of the infection varied from one animal to

Table 3. The virus titre in skin slices taken from the lesions produced by the intradermal inoculation of doses of $10^{4 \cdot 3}$ rabbit-infectious doses of five strains of myxoma virus, all strains being inoculated in each rabbit. Titres expressed as rabbit-infectious doses per $g$. of tissue, in $\log _{10}$ units

\begin{tabular}{|c|c|c|c|c|c|}
\hline \multirow{2}{*}{$\begin{array}{l}\text { Strain of } \\
\text { virus }\end{array}$} & \multirow{2}{*}{$\begin{array}{c}\text { Rabbit } \\
\text { no. }\end{array}$} & \multicolumn{4}{|c|}{ Time after inoculation (days) } \\
\hline & & 6 & 7 & 8 & 10 \\
\hline \multirow[t]{4}{*}{ Standard } & 1 & $8 \cdot 1$ & . & $7 \cdot 4$ & $7 \cdot 8$ \\
\hline & 2 & $7 \cdot 6$ & . & $7 \cdot 2$ & - \\
\hline & 3 & $7 \cdot 3$ & . & $7 \cdot 9$ & . \\
\hline & 4 & $6 \cdot 7$ & . & . & . \\
\hline \multirow[t]{4}{*}{ Neuromyxoma } & 1 & $4 \cdot 2$ & . & $<4 \cdot 2$ & $5 \cdot 5$ \\
\hline & 2 & $5 \cdot 9$ & . & $<4 \cdot 2$ & . \\
\hline & 3 & $4 \cdot 7$ & $6 \cdot 6$ & . & . \\
\hline & 4 & $4 \cdot 2$ & . & . & . \\
\hline \multirow[t]{4}{*}{ KM 13} & 1 & $7 \cdot 6$ & . & $7 \cdot 6$ & . \\
\hline & 2 & $6 \cdot 5$ & . & . & . \\
\hline & 3 & $5 \cdot 9$ & $7 \cdot 8$ & . & . \\
\hline & 4 & $6 \cdot 8$ & . & . & . \\
\hline \multirow[t]{4}{*}{ Uriarra III } & 1 & $7 \cdot 7$ & . & $7 \cdot 8$ & $8 \cdot 4$ \\
\hline & 2 & $7 \cdot 0$ & . & $7 \cdot 6$ & . \\
\hline & 3 & $6 \cdot 8$ & $7 \cdot 7$ & . & . \\
\hline & 4 & $5 \cdot 3$ & . & . & . \\
\hline \multirow[t]{4}{*}{ Lausanne } & 1 & $8 \cdot 7$ & . & $8 \cdot 4$ & $8 \cdot 6$ \\
\hline & 2 & $8 \cdot 1$ & . & $8 \cdot 4$ & . \\
\hline & 3 & $6 \cdot 9$ & $8 \cdot 1$ & . & . \\
\hline & 4 & $7 \cdot 2$ & . & 7.9 & $7 \cdot 8$ \\
\hline
\end{tabular}

another. The skin titres of secondary lesions varied accordingly, and on the same rabbit some lesions sometimes remained fleshy and contained large amounts of virus, whereas others were dry and crusted, and contained little virus. The differences between animals are reflected in the variations seen after the fifteenth day. The real variability was much greater than appears from the few samples tested, for lesions which had not begun to regress were selected for virus recovery. Nevertheless, it is clear that with all the attenuated strains except neuromyxoma, virus was present in high titre for long periods in some skin lesions of some rabbits.

The relative efficiency of mosquitoes in transmitting different strains of virus

Two experimental methods were used to determine whether differences in the relative ease of transmission of various strains of myxoma virus by mosquitoes 
were correlated with differences in the skin titres attained by different strains of virus. The first consisted in allowing numbered, individually tubed mosquitoes, which had previously fed through skin lesions caused by the different virus strains under study, to engorge repeatedly on marked skin sites of susceptible rabbits at intervals of one or more days. The second type of experiment involved a series of probings on susceptible rabbits by mosquitoes which had first probed through skin lesions of rabbits infected with different strains of virus. The details of the second method have been described in the preceding paper (Day et al. 1956).

\section{Repeated feeding on marked skin sites of susceptible rabbits}

Experiments of this type were carried out only with the standard laboratory and Uriarra III strains of myxoma virus and with neuromyxoma virus. The plan of experiment followed exactly that described in our first paper on the transmission of myxomatosis by mosquitoes (Fenner et al. 1952), and the figures for the standard laboratory strain of myxoma virus given in Tables 4 and 5 have been extracted from that paper. The experiment with Uriarra III was carried out by $\mathrm{Dr} R$. Mykytowycz in collaboration with one of us (M. F. Day), and we are indebted to Dr Mykytowycz for permission to include it here. A number of Aedes aegypti were allowed to obtain a blood feed or to probe through the skin lesions produced by the intradermal inoculation of the virus under experiment, at daily intervals after the first appearance of the lesions. They were then given daily opportunities to obtain a blood meal from marked skin sites on susceptible rabbits, which were observed for the development of primary skin lesions at these sites. The results are set out in Tables 4 and 5.

It is clear that mosquito transmission of the standard laboratory and Uriarra III strains of myxoma virus was much more efficient than that of neuromyxoma, a result which agrees well with the skin titres of the three strains. The high frequency of positive results obtained with the rabbit infected with the Uriarra III strain up to the time of its death 19 days after infection is noteworthy, and will be more fully discussed later.

\section{Successive probings by mosquitoes which had probed through infected skin lesions}

The results obtained with Aedes aegypti and two different strains of virus are set out in Tables 6 and 7, and the parameters derived from them are shown in Table 8. The results obtained with the Lausanne strain were reported in the previous paper.

The experiment with neuromyxoma virus gave completely negative results. The donor lesion was used 6 days after inoculation, when its virus content was $10^{4.8}$ rabbit-infectious doses per $\mathrm{g}$. After making three probes on the donor lesion, each of 104 mosquitoes was allowed to probe up to twelve times on marked skin sites on susceptible rabbits - a total of 1220 probes by 104 mosquitoes. To allow the maximum opportunity for transmission all test probes were made immediately after the acquisition probes. No infections occurred.

Considerable variation occurred in the results obtained on different occasions with the same strain of virus (standard laboratory strain). This was probably due to differences in the concentration and distribution of virus particles in the cells of 


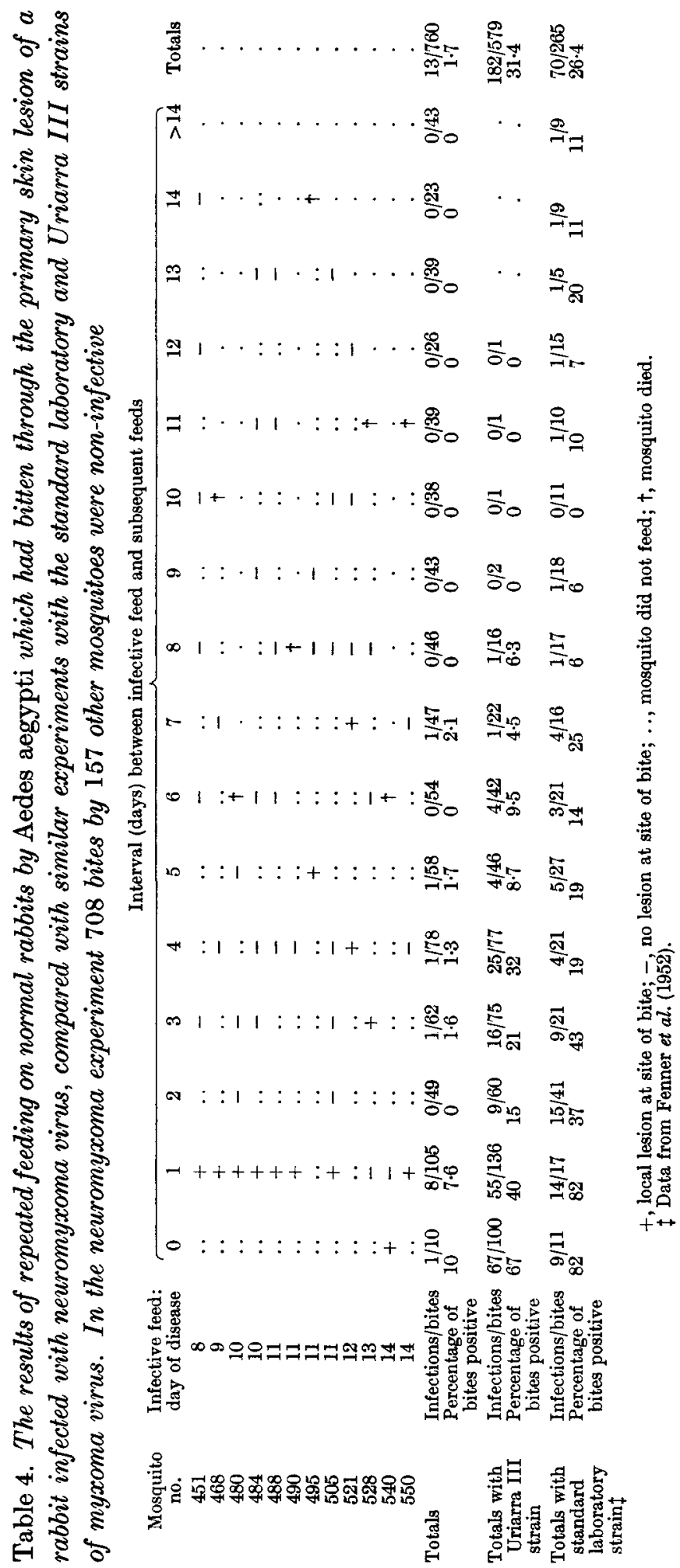


the lesions in the rabbit used for the acquisition feeds, or to variations in the size of mosquitoes belonging to different batches, due to differences in the degree of larval crowding, etc.

There appeared to be no significant differences between the transmissibility of the standard laboratory strain, KM13 and Lausanne, but neuromyxoma was clearly much more difficult to transmit. These results agree, therefore, with the conclusions derived from the titrations of skin slices, and from the mosquito transmission experiments described in the previous section.

Table 5. The relative efficiency of mosquito transmission of neuromyxoma and the standard laboratory and Uriarra III strains of myxoma virus. Mosquitoes probed through the primary skin lesions of rabbits infected with the appropriate virus at various intervals after inoculation, and then fed on marked skin sites on normal rabbits. The first feeds were usually made immediately after the infective probe, and subsequent feeds were taken at intervals of 1, 2 or 3 days

\begin{tabular}{|c|c|c|c|c|c|c|}
\hline \multirow{2}{*}{$\begin{array}{c}\text { Day of } \\
\text { disease in } \\
\text { donor rabbit }\end{array}$} & \multicolumn{2}{|c|}{ Neuromyxoma } & \multicolumn{2}{|c|}{ Uriarra III } & \multicolumn{2}{|c|}{ Standard strain* } \\
\hline & No. & $\%$ & No. & $\%$ & No. & $\%$ \\
\hline Up to 4 & $0 / 33$ & 0 & & . & $0 / 4$ & 0 \\
\hline 5 & $0 / 11$ & $\mathbf{0}$ & & & $4 / 16$ & 25 \\
\hline 6 & $0 / 8$ & 0 & $3 / 7$ & 43 & $9 / 15$ & 60 \\
\hline 7 & $0 / 14$ & 0 & $2 / 13$ & 15 & $12 / 20$ & 60 \\
\hline 8 & $1 / 12 \dagger$ & $8 \cdot 3$ & $11 / 18$ & 61 & $7 / 11$ & 64 \\
\hline 9 & $1 / 16$ & $6 \cdot 3$ & $3 / 16$ & 19 & $10 / 14$ & 71 \\
\hline 10 & $2 / 16$ & 12.5 & $11 / 17$ & 65 & $11 / 12$ & 92 \\
\hline 11 & $4 / 20$ & 20 & $9 / 16$ & 56 & - & - \\
\hline 12 & $1 / 13$ & $7 \cdot 7$ & $13 / 18$ & 72 & - & - \\
\hline 13 & $1 / 10$ & 10 & $9 / 19$ & 47 & - & - \\
\hline 14 & $2 / 16$ & $12 \cdot 5$ & $11 / 17$ & 65 & - & - \\
\hline 15 & & & $13 / 17$ & 76 & - & - \\
\hline 16 & . & . & $10 / 14$ & 71 & - & - \\
\hline 17 & . & . & $16 / 18$ & 89 & - & - \\
\hline 18 & . & . & $15 / 18$ & 83 & - & - \\
\hline Totals & $12 / 169$ & $7 \cdot 1$ & $126 / 208$ & 60.6 & $53 / 92$ & $57 \cdot 6$ \\
\hline
\end{tabular}

* Data from Fenner et al. (1952), Tables 2 and 4.

$\dagger 1 / 12$ indicates that one mosquito was shown to be infective out of twelve mosquitoes tested.

\section{The efficiency of different species of mosquito as vectors of myxomatosis}

The foregoing comparison of the transmission of various strains of myxoma virus by Aedes aegypti showed that, with one exception, all the strains tested were transmitted about equally well by this mosquito, if skin lesions at about the same stage of development were used. The single exception is neuromyxoma which was transmitted very infrequently.

Although it is an excellent laboratory animal, Aedes aegypti is not a natural vector of myxomatosis, at least in Australia. An experiment was therefore set up to compare the efficiency of three species of mosquitoes as vectors, using as the donor animal a single infected rabbit on the same day for all mosquitoes. The donor rabbit had been inoculated 7 days earlier with $5 \times 10^{4}$ rabbit-infectious doses of the 


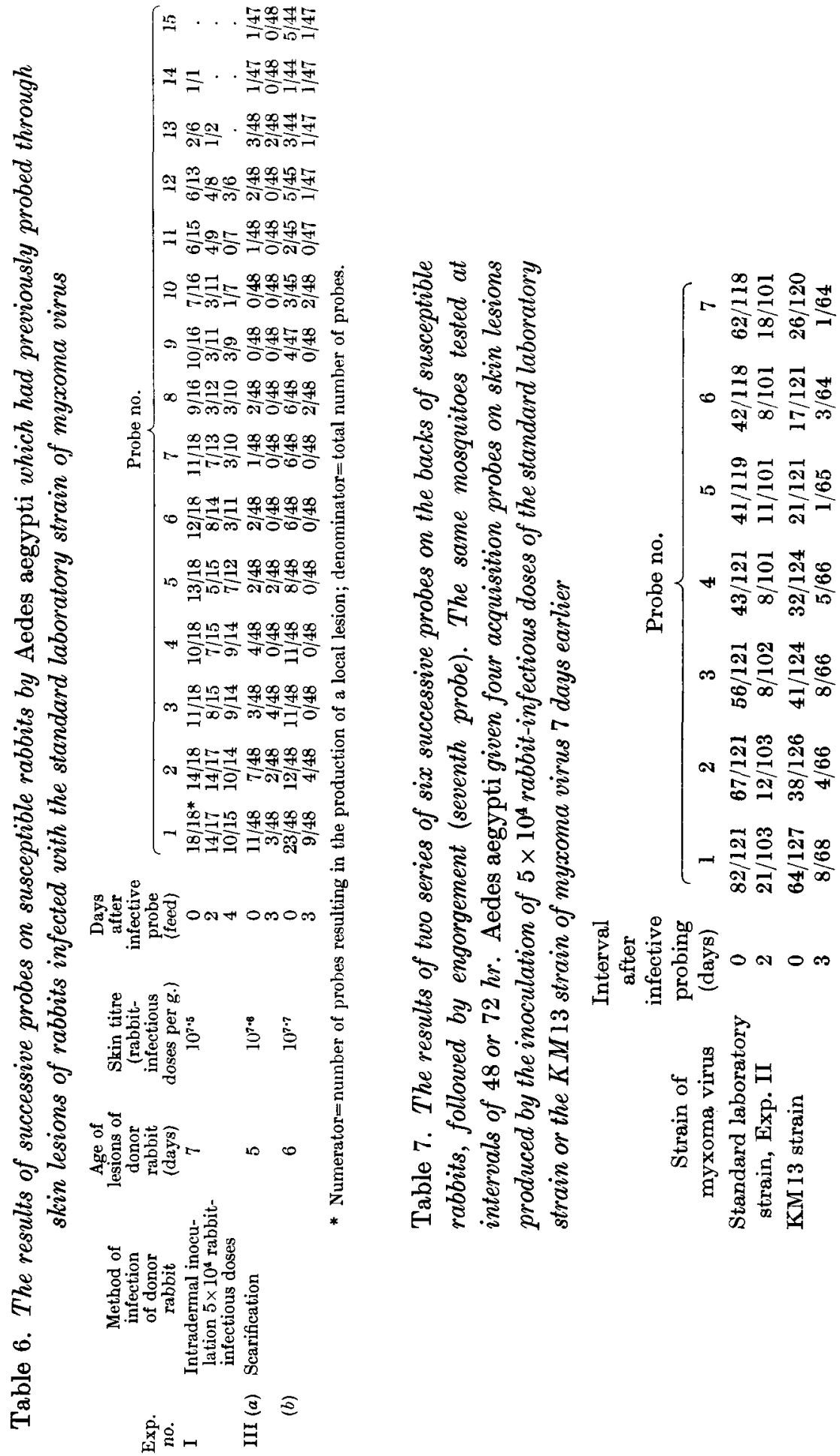


standard laboratory strain of virus. As many mosquitoes as possible of the three species available-Aedes aegypti, Anopheles annulipes, Aedes alboannulatus-were induced to probe three times through the skin lesions, and then allowed to probe up to twenty-one times in succession on the backs of susceptible rabbits. The results are shown in Table 9. The much greater efficiency of the two larger mosquitoes, Aedes alboannulatus and Anopheles annulipes, is apparent. The anatomy of the maxillary stylets of several species of mosquitoes, all actual or potential vectors of myxomatosis, is illustrated in Pl. 6 of Day et al. (1956). The differences observed in these species suggest that correlations between the structure of the maxillary stylets and the efficiency with which a species may transmit myxoma virus may become apparent with further work.

Table 8. Characteristics of the transmission of four strains of myxoma virus by Aedes aegypti

\begin{tabular}{|c|c|c|c|}
\hline Virus strain & $\begin{array}{c}\text { Median minimal } \\
\text { initial virus } \\
\text { load }\end{array}$ & $\begin{array}{l}\text { Amount of virus } \\
\text { lost on } \\
\text { successive probes } \\
\text { (percentage } \\
\text { of load) }\end{array}$ & $\begin{array}{l}\text { Amount of virus } \\
\text { lost per day } \\
\text { (percentage } \\
\text { of load) }\end{array}$ \\
\hline \multicolumn{4}{|l|}{ Standard: } \\
\hline Expt. I & $21 \cdot 6$ & 17 & 15 \\
\hline Expt. II & $4 \cdot 8$ & 22 & - \\
\hline Expt. III (a) & $1 \cdot 3$ & 19 & 45 \\
\hline (b) & $3 \cdot 1$ & - & 一 \\
\hline Neuromyxoma & 0 & - & - \\
\hline KM 13 & $1 \cdot 2$ & 35 & - \\
\hline Lausanne & $7 \cdot 8$ & 12 & 20 \\
\hline
\end{tabular}

Older lesions as a source of virus infections for mosquitoes

Kilham \& Dalmat (1955) found that in fibroma of cottontail rabbits the effectiveness of mosquito transmission was much greater when the virus source consisted of older fibromas (35 days or more), although the virus content was practically unchanged from the 24th to the 142nd day (Kilham \& Fisher, 1954). We had previously found that the skin titre and the virus load of probing mosquitoes were greatest 14 days after the infection of rabbits with the attenuated Uriarra III strain but fell somewhat subsequently (Day et al. 1956). In one of the experiments described earlier in this paper excellent transmission of the Uriarra III strain was observed between the eighth day and the death of the animal 10 days later.

The strains which have become dominant under field conditions in Australia are associated with prolonged survival times in infected rabbits, compared with the standard laboratory strain of virus (Fenner, 1955). The question arose of the infectivity of such rabbits for mosquitoes at longer intervals after infection than those investigated so far. Advantage was taken of the presence in the laboratory of some hundreds of susceptible wild rabbits infected with a small dose of strain KM 13, in an examination of the changes in the innate resistance of wild rabbits to myxomatosis. Two types of investigations were carried out. In the first the virus content of tissue slices taken from secondary lesions was determined, with the results shown in Table 10. The secondary lesions selected for examination were usually small and 


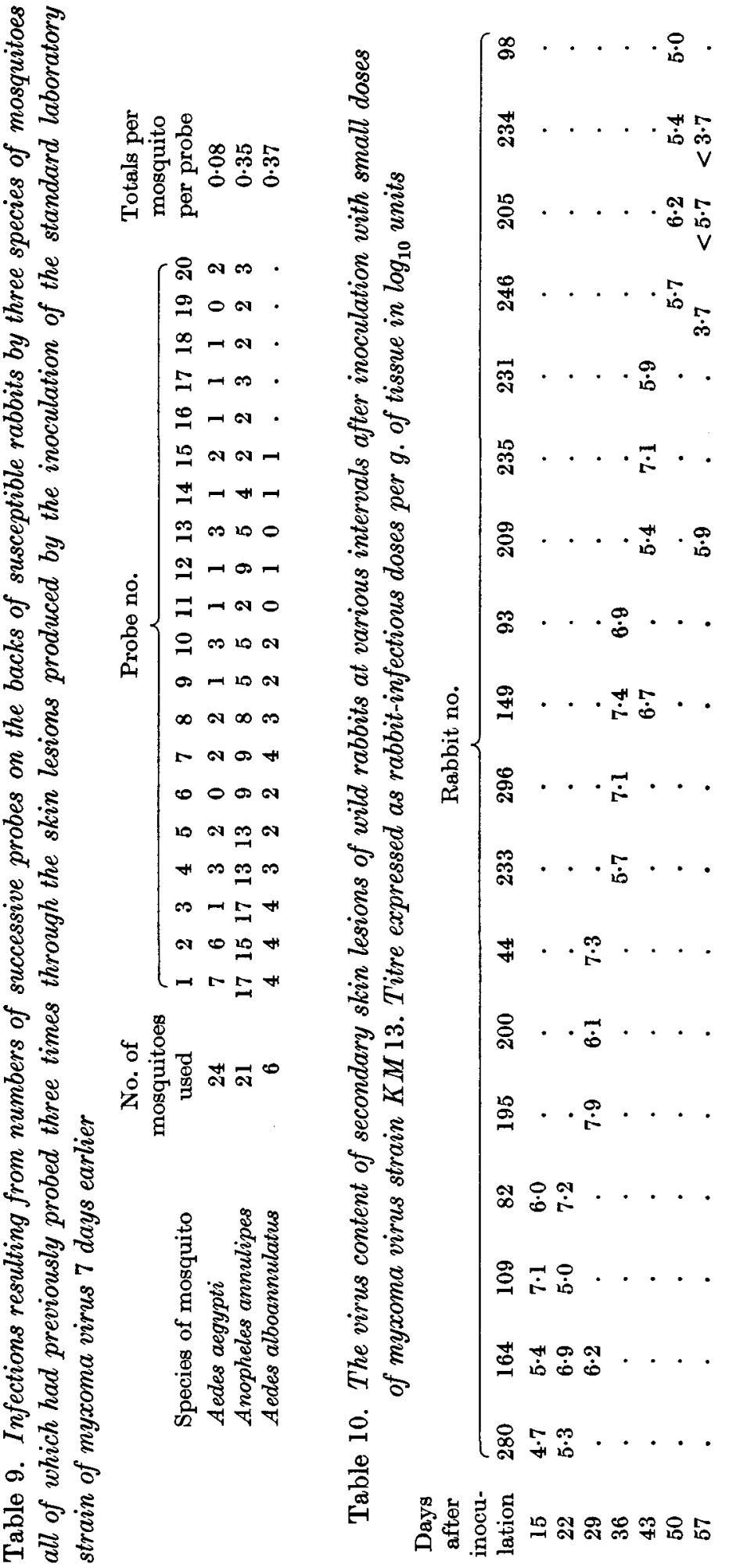


fleshy, except for those of rabbits 234 and 246, on the 57th day after infection. These had started to regress and had become dry and crusted. Virus was present in relatively high concentration in all lesions except those showing obvious regression.

Experiments were also carried out to compare the effectiveness of mosquito transmission from the secondary lesions of wild rabbits infected with strain KM 13. At various intervals after infection several Aedes aegypti were induced to probe through secondary skin lesions comparable with those titrated previously. Each mosquito was then allowed to take a blood meal on a marked skin site of a susceptible rabbit, and the development of local lesions was observed. The results are recorded in Table 11. They indicate that infectivity for mosquitoes runs parallel with virus titre, and that transmission could be demonstrated with about the same frequency from all lesions except those which were obviously regressing (R 546 and R 566). Until their lesions regress and become dry and crusted, rabbits infected with the slightly attenuated strains of myxoma virus of the KM13 type remain infectious for mosquitoes.

Attenuated variants of the strain of myxoma virus responsible for the European epizootics have only recently been recognized (Fenner \& Marshall, 1955). Some experiments similar to, but less detailed than, those just described have been carried out with one of these attenuated European strains and also with the Uriarra strain which is distinctly less virulent than most Australian field strains. Rabbits inoculated with Loiret 55 and Uriarra III were used as donor rabbits in mosquito transfer experiments carried out 18 and 24 days after inoculation. Groups of about fifty mosquitoes were allowed to probe three times through the skin lesions and were then allowed to engorge on marked sites on the backs of normal rabbits. The results are shown in Table 12.

The abrupt fall in the virus concentration of Uriarra III strain was accompanied by poor mosquito transmission, whereas the skin titre of Loiret 55 was maintained at a high level for a prolonged period, and was a rich source of virus for mosquitoes.

\section{The effect of alternate feeding on diseased and immune rabbits on transmission}

In an earlier paper (Fenner \& Marshall, 1954) the possibility was discussed that feeding on an immune rabbit after probing or feeding through an infectious lesion might neutralize some of the virus on the mouthparts, and that the presence of large numbers of immune rabbits in a population might therefore have an epidemiological effect in excess of their dilution of the susceptible population. This was examined experimentally in the following manner. Twenty-two mosquitoes which had probed through the skin lesion of a myxomatous rabbit 7 days after inoculation with standard laboratory strain-skin titre $10^{7 \cdot 9}$ rabbit-infectious doses per g.were immediately allowed to take a blood meal on a marked site on a normal rabbit, and another twenty were allowed to feed on a myxoma-immune rabbit, the serum of which produced a $99 \cdot 2 \%$ reduction in the pock count on the chorioallantois. Nineteen of the twenty-two mosquitoes allowed to take a blood meal from a normal rabbit immediately after the acquisition probing produced local lesions on the sites of their biting, whereas no lesions appeared on the myxoma-immune 


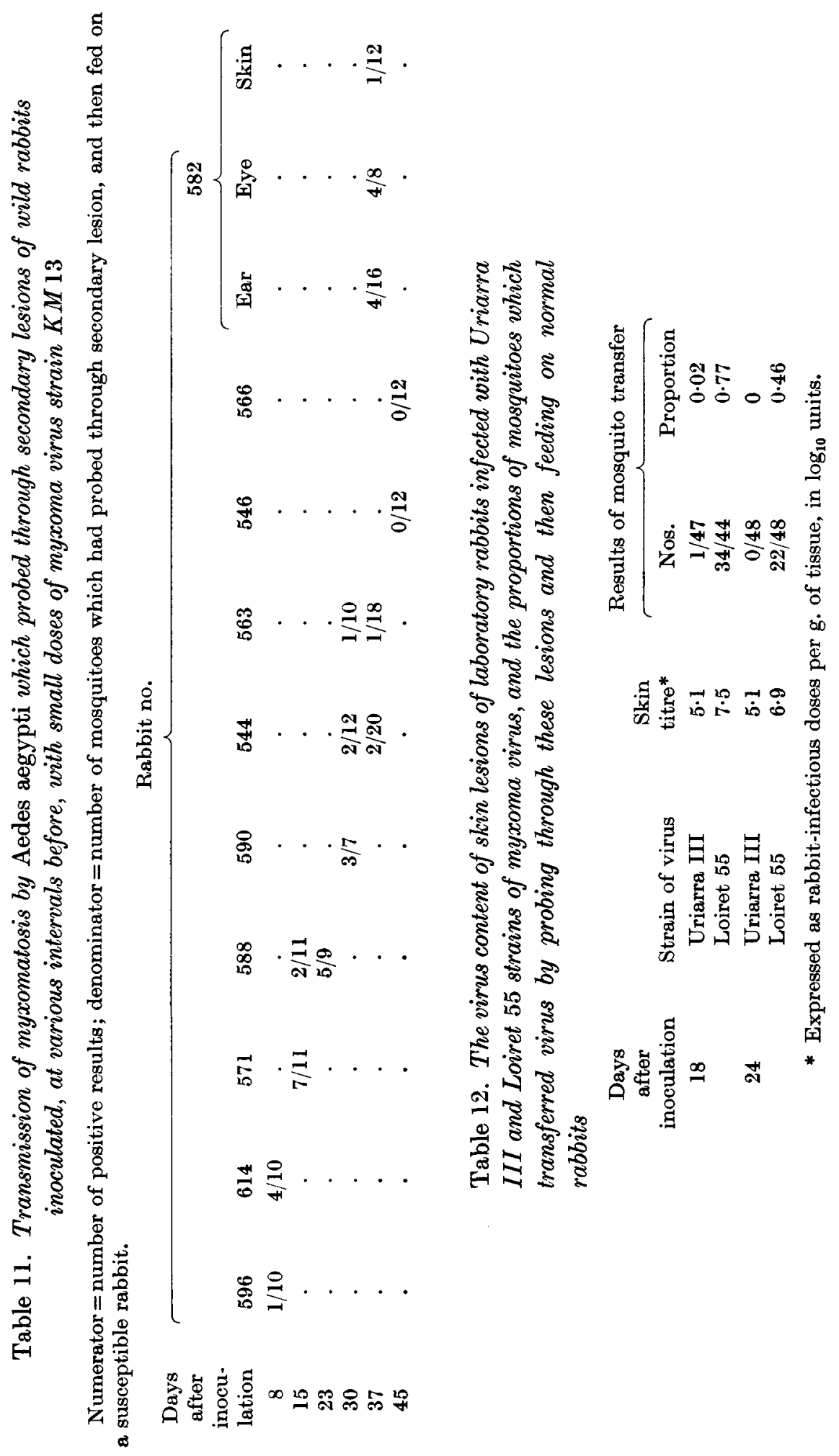


rabbit. Two days later each mosquito was induced to probe seven times on marked sites on the backs of normal rabbits, taking a blood feed on the seventh site. Table 13 shows that thirty-eight out of 105 probes by the fifteen mosquitoes which had obtained a blood meal on the normal rabbit proved infectious, and fifty out of 119 of those fed 2 days earlier on an immune rabbit were positive. Examination of the proportion positive at each successive probe confirms the results of the comparison of the total numbers of positive probes in the two groups. This experiment shows that a subsequent blood meal on an immune rabbit has no effect on the virus load on the mouthparts of infected mosquitoes greater than that produced by a blood meal taken from a normal animal.

Table 13. The effect on the efficiency of transmission of myxomatosis of a blood meal taken from a myxoma-immune rabbit immediately after mosquitoes had probed through the skin lesions of an infected rabbit. Probes and blood meal on test rabbits made 2 days after feeding on the normal or immune rabbit

\begin{tabular}{|c|c|c|c|c|c|c|c|c|c|}
\hline & & & & & robe $n$ & & & & \\
\hline Group & $\begin{array}{c}\text { No. of } \\
\text { mosquitoes }\end{array}$ & 1 & 2 & 3 & 4 & 5 & 6 & $\begin{array}{c}7 \\
\text { (blood } \\
\text { meal) }\end{array}$ & Total \\
\hline $\begin{array}{l}\text { First blood meal } \\
\text { on normal rabbit }\end{array}$ & 15 & $\begin{array}{l}7^{*} \\
0 \cdot 47 \dagger\end{array}$ & $\begin{array}{l}5 \\
0 \cdot 33\end{array}$ & $\begin{array}{l}5 \\
0 \cdot 33\end{array}$ & $\begin{array}{l}4 \\
0 \cdot 27\end{array}$ & $\begin{array}{l}6 \\
0 \cdot 40\end{array}$ & $\begin{array}{l}5 \\
0 \cdot 33\end{array}$ & $\begin{array}{l}6 \\
0 \cdot 40\end{array}$ & $\begin{array}{l}38 \\
0 \cdot 36\end{array}$ \\
\hline $\begin{array}{l}\text { First blood meal } \\
\text { on immune rabbit }\end{array}$ & 17 & $\begin{array}{l}10 \\
0 \cdot 59\end{array}$ & $\begin{array}{l}6 \\
0 \cdot 35\end{array}$ & $\begin{array}{l}5 \\
0 \cdot 30\end{array}$ & $\begin{array}{l}6 \\
0 \cdot 35\end{array}$ & $\begin{array}{l}8 \\
0.47\end{array}$ & $\begin{array}{l}6 \\
0 \cdot 35\end{array}$ & $\begin{array}{l}9 \\
0 \cdot 53\end{array}$ & $\begin{array}{l}50 \\
0 \cdot 42\end{array}$ \\
\hline
\end{tabular}

* Number of probes producing local lesions.

$\dagger$ Proportion of probes producing local lesions.

Serial transmission of myxoma virus by Aedes aegypti

Andrewes (personal communication, 1954) suggested that the maintenance of high virulence by myxoma virus in Europe, and the attenuation of the Australian strain (Fenner \& Marshall, 1956) might be due to modifications occurring during the serial passage of the latter by mosquitoes, with the implication that myxoma virus multiplied in the mosquito. Such changes might not occur if the principal vector was the rabbit flea, as is said to be the case in Britain. In the preceding paper (Day et al. 1956) we reported that there was no evidence of multiplication of the standard laboratory strain of myxoma virus in either Aedes aegypti or Anopheles annulipes. Nevertheless, we carried out several serial mosquito passages of this strain of virus, allowing 2 weeks to elapse betewen the acquisition and infective feeds. The lack of a laboratory colony of Anopheles annulipes precluded its use, and the experiments were carried out with Aedes aegypti. The general plan was as follows. A number of mosquitoes were allowed to take a blood feed through the skin lesions of the donor rabbit 7 days after it had been infected, and were released into a cage and maintained at $23^{\circ} \mathrm{C}$. for 14 days, feeding on sugar and water. They were then allowed to take blood feeds on the shaved back of a normal rabbit and were subsequently ground in small glass grinders without alundum, and stored at $-20^{\circ} \mathrm{C}$. On the first attempted passage no lesions appeared on the normal rabbit after the feeding of the infected mosquitoes; the suspension of ground-up mosquitoes 
was inoculated and produced a specific lesion. On all subsequent occasions infection was established by feeding. The lesions resulting from mosquito bites or the inoculation of mosquitoes were used as the acquisition sites for the succeeding batch of mosquitoes. Tissue slices were taken from each rabbit, so that the standard tests for virulence could be conducted (Fenner \& Marshall, 1956), and the course of the disease in each mosquito-infected rabbit was carefully observed. The appearance of the local lesions appearing at the site of the mosquito bites, and the progress of the disease in the rabbits infected by biting, always conformed to the symptomatology associated with the standard laboratory strain of virus. Subinoculation

Table 14. Successive rabbit-mosquito-rabbit passages of the standard laboratory strain of myxoma virus, allowing 7 days before Aedes aegypti were fed on the primary lesions induced by the bites of the previous group of mosquitoes, and 14 days at $23-28^{\circ} \mathrm{C}$. before the infected mosquitoes were allowed to feed on a susceptible rabbit

\begin{tabular}{|c|c|c|c|c|c|}
\hline \multirow[b]{2}{*}{$\begin{array}{l}\text { Time from } \\
\text { onset of } \\
\text { experiment } \\
\text { (weeks) }\end{array}$} & \multirow[b]{2}{*}{$\begin{array}{l}\text { 'Mosquito } \\
\text { passage' } \\
\text { number }\end{array}$} & \multirow[b]{2}{*}{$\begin{array}{c}\text { Mosquitoes } \\
\text { Fed on donor* } \\
\text { Fed on recipient }\end{array}$} & \multicolumn{2}{|c|}{ Recipient rabbit } & \multirow[b]{2}{*}{$\begin{array}{l}\text { Virulence } \\
\text { of virust }\end{array}$} \\
\hline & & & $\begin{array}{l}\text { No. of } \\
\text { primary } \\
\text { lesions }\end{array}$ & $\begin{array}{c}\text { Day of } \\
\text { death }\end{array}$ & \\
\hline 3 & . & $35 / 12$ & 0 & . & $11 \cdot 1 \ddagger$ \\
\hline 4 & 1 & $12 \S$ & + & 10 & 10,13 \\
\hline 7 & 2 & $33 / 15$ & 1 & 10 & $11,12,12$ \\
\hline 10 & 3 & $40 / 33$ & 3 & 11 & $9,10,12$ \\
\hline 13 & 4 & $40 / 30$ & 2 & 10 & \\
\hline 16 & 5 & $35 / 27$ & 7 & 10 & $13,14,15$ \\
\hline 19 & 6 & $54 / 46$ & 8 & 10 & $12,12,13$ \\
\hline 22 & 7 & $53 / 9$ & 1 & 9 & $10,11,11$ \\
\hline 25 & 8 & $35 / 20$ & 6 & 10 & $9,9,14$ \\
\hline 30 & 9 & $83 / 13$ & 2 & 10 & $11,11,12$ \\
\hline
\end{tabular}

* Donor rabbit $=$ rabbit with 7-day-old primary lesions resulting from bites of previous group of mosquitoes. Recipient rabbit = normal rabbit bitten by the number of mosquitoes indicated.

$\dagger$ Expressed as survival time in days after the inoculation of about five rabbit-infectious doses of lesion material taken from the appropriate recipient rabbit.

$\ddagger$ Mean of forty rabbits infected with small doses of the standard laboratory strain.

$\S$ Suspension of mosquitoes which failed to transmit by bite produced a lesion on inoculation.

from the mosquito-infected rabbits showed that no change in virulence had occurred, nor did the symptomatology of the inoculated rabbits vary from that found in infections with the standard laboratory strain of virus. The results are presented in Table 14.

Thus the standard laboratory strain of myxoma virus was carried through nine successive mosquito-rabbit-mosquito passages, in each of which it multiplied for 7 days in a rabbit before being acquired by a mosquito; and was resident in a mosquito for 14 days at $23-28^{\circ} \mathrm{C}$. before being passed to another rabbit. No change of virulence or pathogenic behaviour occurred. Groups of twenty mosquitoes of the ninth 'mosquito passage' were ground and titrated 4 and 28 days after their acquisition feed. The virus titres on the two occasions were sixty and two 
rabbit-infectious doses of virus per twenty mosquitoes, i.e. there was no evidence of multiplication, although virus persisted for a prolonged period in some mosquitoes. The latter fact was confirmed by the two lesions produced by thirteen of the original eighty-three mosquitoes which fed on a normal rabbit 31 days after their acquisition feed.

\section{DISCUSSION}

The evolution of myxomatosis as a disease of Oryctolagus cuniculus depends on changes in both host and virus. Since the most important transmission mechanism, at least in Australia, is by mosquito bite, any adjustments in virus behaviour which favour mosquito transmission should have a selective advantage. The experiments reported in this paper support this view, and explain the present (1955) dominance of slightly attenuated strains of virus. Titrations of tissue slices showed that, except for the greatly attenuated neuromyxoma strain, all other strains examined produced about the same concentrations of virus in the skin between the seventh and fourteenth days after inoculation, and were equally well transmitted by mosquitoes. Slightly attenuated strains like KM 13 or Loiret 55 permitted survival of infected rabbits in a highly infectious state (for mosquitoes) for several weeks, thus giving such strains definite advantages over the highly virulent standard laboratory strain and European (Lausanne) strain. More attenuated Australian field strains of the Uriarra type, which do not appear to have spread very widely (Fenner \& Marshall, 1956), produced in some rabbits a disease associated with high skin titres until about the sixteenth or eighteenth day. A rapid fall then occurred coincident with healing of the skin lesions, so that the period of high infectivity of such rabbits for mosquitoes was limited to about 7 days. Other animals appeared to provide rich sources of virus for mosquitoes for prolonged periods. The apparent dominance of the KM 13 over the Uriarra III type under field conditions in Australia must depend upon differences too subtle to be apparent from the crude type of assessment used here.

The approximate periods of high infectivity of the different strains studied are shown in Table 1, from which it can be seen that rabbits infected with slightly attenuated strains like KM 13 are potentially infectious for mosquitoes for about five times as long as those infected with the fully virulent strains. The reality of this advantage is borne out by the fact that, in spite of the annual inoculation of large numbers of wild rabbits with the standard laboratory strain of virus, the great majority of strains of virus recovered from the field in Australia during the last 4 years have been of the KM 13 type, i.e. slightly attenuated (Fenner \& Marshall, 1956). Further, when the slightly attenuated local strain and the European strain were placed in competition at Lake Urana, the local strain finally replaced the European strain, in spite of the fact that the preponderance of cases at the beginning of the epizootic were of the latter type (Fenner, Poole, Marshall \& Dyce, 1956).

Natural selection for the virus depends in large part on the relative efficiency of transmission of different variants by mosquitoes. Transmission is favoured by extensive skin lesions containing a high virus titre for a prolonged period, in a sick 
rabbit, which will fail to dislodge mosquitoes. Consideration of the facts discussed in this paper, and summarized in Table 1 and Fig. 1, explain the present dominance of the KM 13 type of virus in Australia, and lead one to expect that viruses like Loiret 55 will soon become widespread in Europe.

Although vector specificity (in the form of the ability of a vector to support multiplication of the virus) does not enter into mechanical transmission, various factors make some mosquitoes much more important as vectors than others. The principal reasons are differences in feeding preferences, in density, and in behaviour patterns (flight range, resting places, etc.), but the experiments reported in this paper show differences which are probably related to the anatomy of the mosquito's stylets. In the course of these experiments differences in the feeding behaviour of Aedes aegypti and Anopheles annulipes were observed, which, if they occurred in nature, might affect vector efficiency. $A$. annulipes probed more deeply and appeared much more likely to resume attempts to feed after it had imbibed a small amount of blood than did Aedes aegypti. Deep probing, and persistent attempts to feed after interruption, would undoubtedly favour the transmission of myxomatosis.

The calculations summarized in Table 8 suggest that the dose of virus deposited by a mosquito is usually very small. Occasionally a mosquito carrying a very heavy load of virus on the proboscis may deposit 100 infectious units or thereabouts of the virus in the skin of the rabbit, but the dose must usually be very much smaller, and infections by single virus particles are probably fairly common. The experiment summarized in Table 7 indicated that there was a greater likelihood of infection from a mosquito which engorged on a rabbit than from one which merely probed and then withdrew its proboscis. The data in this experiment suggested that the chance of infection of a susceptible rabbit when a mosquito took a blood feed was about twice that resulting from a probe.

If virus particles adhere to parts of the proboscis, and a mosquito carrying virus subsequently engorges on an immune rabbit, one might expect that not only would some virus be lost into the tissues of the rabbit, but that antibody in the serum and tissue fluids of the immune animal might neutralize some or all of the virus remaining on the proboscis. The experiment reported here shows that this did not occur, and the epidemiological effect of immune rabbits in a population is thus confined to their diluting effect on the proportion of potentially infectious bites.

The pattern of mosquito-borne myxomatosis epizootics suggests that just before and at the peak of the epizootic there are great numbers of infected mosquitoes, and that they transmit without an appreciable latent period. We have nevertheless examined the possibility that some modification might occur during serial passage of the virus through rabbits infected by mosquito bite, if 2 weeks were allowed to elapse before the infected mosquitoes could bite a susceptible rabbit. Nine such passages, which occupied a total period of 7 months, failed to produce any detectable change in the virus.

One further comment may be made on the epidemiology of myxomatosis. Shope (1954) said 'to judge from the manner in which it [the myxoma virus] is performing and persisting in its new territory [Australia] it has found intermediate hosts and a 
satisfactory reservoir host, at present not well understood, without apparent evolution of any of the various factors which must be involved in its ecology'. In Australia, where there is a very large wild rabbit (Oryctolagus cuniculus) population spread over an area of hundreds of thousands of square miles, and a variety of efficient and mobile insect vectors, there is no reason to believe that myxomatosis is being maintained other than by direct Oryctolagus transfer, usually via an arthropod vector but sometimes by direct contact. The situation in Europe is similar. In Brazil and California, on the other hand, where $O$. cuniculus occurs only as a domesticated animal, it is clear that persistence of the disease must depend on a reservoir host-Sylvilagus braziliensis in Brazil (Aragao, 1943) and perhaps Sylvilagus bachmani in California (Calaby, unpublished). Indeed, in the Americas, myxomatosis should be regarded as a disease of Sylvilagus rabbits, maintained in them by arthropod transfer, which occasionally escapes into the domesticated Oryctolagus populations. Only then is its existence recognized by man.

\section{SUMMARY}

When examined under similar conditions in the laboratory, the two strains of myxoma virus used to initiate the Australian and European epizootics, and three somewhat attenuated strains recovered in the field in Australia and France, were found to produce lesions containing approximately the same amount of virus, and were transmitted by mosquitoes with approximately equal efficiency. The laboratory variant neuromyxoma multiplied poorly in the skin and was very rarely transmitted by mosquitoes.

The survival potential of different virus strains in the field is correlated with the length of time during which rabbits infected with different strains present to biting mosquitoes lesions containing high concentrations of virus. Sickness of the infected rabbit, and extensive viruliferous skin lesions, will increase its suitability as a source of virus for mosquitoes. These considerations explain the dominance of slightly attenuated strains of myxoma virus in the field in Australia.

Species of mosquitoes, when tested under standard conditions in the laboratory, differ in their efficiency as vectors of myxomatosis. These differences may be related to differences in the method of feeding, and to structural differences in the mouthparts.

Engorgement on an immune rabbit after probing through myxomatous skin lesions had no greater effect on the subsequent ability of mosquitoes to transmit myxomatosis than a similar blood feed on a normal rabbit.

Nine serial mosquito-bite passages of the standard laboratory strain of virus, each involving one week in the rabbit and two weeks in the mosquito, had no effect on its pathogenic behaviour.

We are indebted to Mr G. A. McIntyre, Division of Mathematical Statistics, C.S.I.R.O., for analysis of the results obtained in the experiments involving repeated probing by mosquitoes. 


\section{REFERENCES}

Aragao, H. De B. (1943). Mem. Inst. Osw. Cruz. 38, 93.

Bouvier, G. (1954). Personal communication.

Chamberlain, R. W., Corristan, E. C. \& Sikes, R. K. (1954). Amer. J. Hyg. 60, 269.

Chamberlain, R. W., Kissling, R. E. \& Sikes, R. K. (1954). Amer. J. Hyg. 60, 286.

Chamberlain, R. W., Sikes, R. K., Nelson, D. B. \& Sudia, W. D. (1954). Amer. J. Hyg. $60,278$.

Day, M. F., Fenner, F., Woodroofe, G. M. \& McIntyre, G. A. (1956). J. Hyg., Camb., $54,258$.

FeNNer, F. (1955). J. Aust. Inst. agric. Sci. 21, 137.

Fenner, F., Day, M. F. \& Woodroofe, G. M. (1952). Aust. J. exp. Biol. med. Sci. 30, 139.

Fenner, F. \& Marshall, I. D. (1954). J. Hyg., Camb., 52, 321.

Fenner, F. \& Marshall, I. D. (1955). Nature, Lond., 176, 782.

Fenner, F. \& Marshall, I. D. (1956). In preparation.

Fenner, F., Poole, W. E., Marshall, I. D. \& Dyce, A. L. (1956). In preparation.

Fenner, F. \& McIntyre, G. (1956). J. Hyg., Camb., 54, 246.

Fenner, F. \& Woodroofe, G. M. (1953). Brit. J. exp. Path. 34, 400.

Hurst, E. W. (1937). Brit. J. exp. Path. 18, 15.

Km.Ham, L. \& Dalmat, H. T. (1955). Amer. J. Hyg. $61,45$.

Kilham, L. \& Fisher, E. R. (1954). Amer. J. Hyg. 59, 104.

Lush, D. (1937). Aust. J. exp. Biol. med. Sci. 15, 131.

Moses, A. (1911). Mem. Inst. Osw. Cruz. 3, 46.

Myers, K., Marshall, I. D. \& Fenner, F. (1954). J. Hyg., Camb., 52, 337.

MyкYтоwycz, R. (1953). Nature, Lond., 172, 448.

Schaeffer, M. \& Arnold, F. H. (1954). Amer. J. Hyg. 60, 231.

Shope, R. E. (1954). In The Pathogenesis of Viral and Rickettsial Infections, ed. F. W. HARTman, F. L. Horsfall, \& J. G. Kidd. New York: The Blakiston Co.

(MS. received for publication 28. XI. 55) 